\title{
Capoeira: a memória social construída por meio do corpo
}

\author{
Igor Márcio Corrêa Fernandes da Cunha* \\ Luiz Renato Vieira** \\ Luiz Carlos Vieira Tavares*** \\ Tânia Mara Vieira Sampaio****
}

\begin{abstract}
Resumo: O objetivo desta pesquisa foi compreender, por meio de uma análise de elementos da história da capoeira, alguns mecanismos de busca por legitimação no seu universo, bem como suas diferentes formas de organização e manifestação preservadas na memória e cultura brasileira. Utilizamos a memória social como instrumento analítico reflexivo, para compreender melhor os processos de formação das identidades em uma nação. O texto traz as diferentes memórias construtoras das vertentes da capoeira brasileira em diálogo com seu recente registro como patrimônio imaterial da cultura brasileira.
\end{abstract}

Palavras Chave: Capoeira. Memória. Características culturais.

\section{INTRODUÇÃo}

A memória social conforma-se por meio de disputas que agentes sociais, representantes de determinados interesses, travam para fixar o que é realmente importante para ser imortalizado nos livros e demais registros de um país. Os agentes buscam, por meio de suas memórias, fazer com que a história passe por um processo de socialização. A reflexão sobre os valores e saberes que

\footnotetext{
*Programa de Pós-graduação em Educação Física. Universidade Católica de Brasília. Brasília, DF, Brasil. E-mail: igorfcunhaedf@gmail.com

**Senado Federal. Área de Desporto e Cultura. Brasília, DF. Brasil E-mail: Ir.luizrenato@gmail. com

***Instituto Federal de Sergipe. Aracajú, SE, Brasil. E-mail: mestrelucastavares@hotmail.com ****Programa de Pós-Graduação em Educação Física. Universidade Católica de Brasília. Brasília, DF. Brasil E-mail: taniamara_sampaio@hotmail.com
} 
participam da construção das sociedades contemporâneas passa necessariamente por um exame da relação da memória e da cultura com o poder. A memória é um importante instrumento para a construção, enfrentamento ou superação de ideologias no decorrer da história (POLLAK, 1992).

Nessa discussão a respeito da memória, há que se considerar ainda que, na sociedade contemporânea, as múltiplas identidades nas nações modernas, com seus grupos particulares, partidos, sindicatos e associações, estão em constantes articulações para formar uma coesão social, em busca de atenção às suas causas. Nesse contexto, Antônio Sá em diálogo com os estudos de Pierre Nora (1997) , afirma que "a memória nacional não é então uma experiência definitiva, um repertório fechado, mas sim um campo de forças em constante elaboração e perpétuo remanejamento" (SÁ, 2003, p.174).

No esporte, na cultura, assim como nas questões especificamente políticas, existem indivíduos e ou atletas que serão lembrados e os feitos que serão imortalizados. E nesse campo social, atores trabalham para que determinadas memórias sejam fortalecidas ou apagadas. Dentro desse contexto cultural esportivo, quando tratamos a temática da memória social e do corpo, surgem naturalmente questionamentos como: o que deve ser realmente memorável? Quais os gestos e formas são enaltecidos? Como a memória é utilizada e praticada? Quais as questões que entraram em esquecimento? Quais elementos corporais caíram em desuso? Quais pontos são passíveis de construções seletivas? Quais fatos devem ser comemorados? Como as comemorações e seus formatos podem influenciar na formação de uma identidade nacional? Tais questionamentos são respondidos e habilidosamente articulados na dimensão política da memória e dos valores pessoais dos sujeitos envolvidos.

Embora seja, atualmente, desnecessário reafirmar o caráter cultural do corpo e do movimento humano, há importantes

${ }_{1}^{1}$ NORA, Pierre. L'ére de La commémoration. In NORA, Pierre (dir.). Les Lieux de Mémoire (Les Frances). Paris: Gallimard, 1997. v. 3.

Movimento, Porto Alegre, v. 20, n. 2, p. 735-755, abr./jun. de 2014. 
aspectos a serem destacados, para efeito das reflexões que se seguem. Reforçam-se os vínculos entre corporeidade e construção da memória à medida que entendemos o corpo não apenas como o suporte fisiológico do ser, mas, sobretudo, como um dos mais importantes veículos de manifestação da cultura. A relação corpocultura foi, no campo das ciências sociais, apontada inicialmente pelo antropólogo Marcel Mauss (1974), que salientava o fato de que da forma de caminhar às posições sexuais, nada é mais cultural do que o uso do corpo.

Assim, os esportes e as manifestações culturais caracterizadas por acervos gestuais complexos - das quais a capoeira é um caso típico - tornam-se relevantes temas de estudos da memória social. A capoeira, portanto, pode ser observada como estrutura que exemplifica bem os processos de organização das memórias e da legitimação social por meio de um universo gestual e cênico. A escolha desse objeto de estudo é embasada em dois fatos principais.

Em primeiro lugar, a capoeira possui significativa representatividade na cultura brasileira e no mundo, sendo considerada atualmente como um fenômeno popular cultural internacional (VIEIRA, 2002). A capoeira está inserida em mais 150 países em contextos múltiplos, além de ter se tornado objeto de reflexão acadêmica em diversas áreas do conhecimento. E obteve também alguns de seus elementos registrados como patrimônio cultural imaterial brasileiro e pode ser percebida, nos dias de hoje, nos palcos de teatro, salas de cinema e anúncios de publicidade (VIEIRA; ASSUNÇÃO, 2009). Vista como uma difusora expressiva da língua portuguesa para o mundo, por meio de suas terminologias e cantigas ensinadas em nossa língua. Devido a seu alcance internacional, dentro da comunidade capoeirística, cada grupo reivindica sua memória, reivindica sua parte no cenário nacional em torno do seu passado.

Em segundo lugar, a capoeira traz um importante embate no campo de disputas e resgate da memória dos chamados "velhos mestres" e sua oralidade. No ambiente da capoeiragem, mais do

Movimento, Porto Alegre, v. 20, n. 2, p. 735-755, abr.jun. de 2014. 
que na maioria das outras manifestações culturais, seus praticantes realizam essa busca de maneira ímpar, por meio de uma procura infindável pelo conhecimento de sua origem e de sua história. Há um respeito admirável aos patronos da modalidade e aqueles que receberam a transmissão direta dos conhecimentos, sem falar dos grandes nomes imortalizados nas cantigas.

O objetivo desta pesquisa, portanto, foi compreender, por meio de uma análise de elementos da história da capoeira, alguns mecanismos de busca por legitimação no seu universo, bem como suas diferentes formas de organização e manifestação preservadas na memoria e cultura brasileira. Dentre esses mecanismos de busca por legitimação, tem destaque especial a construção do discurso: muitas vezes, fatos passados são trazidos à luz do presente, de maneira a dar coerência cronológica para os que discursam e que desejam construir um sentimento de identidade nas pessoas. Dessa forma, por meio dos exemplos encontrados na capoeira e na sua memória debateremos o entendimento de realidades construídas, relacionadas a esse universo pluralizado, o qual conta com a existência de um forte caráter eletivo no registro da história e ainda é cercado por diversos construtos sociais.

A metodologia adotada na pesquisa foi exploratória, descritiva e qualitativa, utilizando os fundamentos teórico-metodológicos da pesquisa em memória social (POLLAK, 1992). A organização teve como base diversas fontes bibliográficas, relacionadas aos aspectos históricos da capoeira, às formas de organização do seu universo e também as relativas aos processos para tornar-se patrimônio imaterial.

A pesquisa assumiu também um caráter de observação participante, pois o convívio com a capoeira ao longo das décadas serviu como fator facilitador para organização das ideias e conteúdo. O breve apanhado histórico não teve intenção de um mapeamento historiográfico, e sim, o intuito de emoldurar o processo de organização da capoeira e atentar para sua pluralidade. Buscouse, também, salientar o momento em que a capoeira recebendo o

Movimento, Porto Alegre, v. 20, n. 2, p. 735-755, abr./jun. de 2014. 
registro patrimonial como cultura brasileira gerou polêmicas nesse universo multifacetado.

\section{Os DISTINTOS MOVIMENTOS DA CAPOEIRA NO BRASIL}

Após o período da abolição, a mão de obra negra livre encontrou sérios obstáculos para integrar-se à economia formal devido aos séculos de tradição escravocrata. Assim, seguiam os capoeiristas vivendo marginalmente na sociedade e ilustrando páginas policiais, principalmente no Rio de Janeiro e São Paulo. Cercada de contradições, a capoeira cresceu não somente em direção ao envolvimento com a política e em processos de criminalização, como também cresceu em número de adeptos livres e brancos nesse período (SOARES, 1996). Dessa forma, promoveu, em determinadas regiões do país, o contato entre pessoas de diferentes origens sociais, étnicas e nacionais, desencadeando intensas trocas culturais.

A capoeira configurou-se como herança escrava que se desenvolvia, cada vez mais, mestiça. A mestiçagem trazia uma conotação de nacionalidade e miscigenação, ofuscando lentamente a origem negra. Corroborando esse ponto de vista, Simone Vassallo (2003) traz uma importante visão dos intelectuais e escritores da época, exemplificado pelo pensamento de Mello Morais Filho, quando afirmou: "os negros eram considerados primitivos, e suas atividades eram classificadas como patológicas. A capoeira era um 'cancro moral' que deveria ser extirpado, pois impedia a modernização do país" (MORAIS FILHO,1893², p.431, apud VASSALO, 2003, p. 108). A capoeira avançou no século XX dentro de movimentos contraditórios, inserida em um processo de renovação de seus sentidos sociais, disseminando a cultura negra e colocando-a em contato com outras matrizes culturais, buscando caminhos distintos à procura de aceitação. Proibida pelo Código Penal no início da República, pelo decreto n 487 de outubro de

${ }^{2}$ MORAIS FILHO, Alexandre Mello. Capoeiragem e capoeiras célebres, em Festas e tradições populares. Rio de Janeiro: H. Garnier, 1893.

Movimento, Porto Alegre, v. 20, n. 2, p. 735-755, abr.jun. de 2014. 
1890, recebeu status diferenciado no capítulo XIII, denominado: "dos vadios e capoeiras". Ela era tida como uma "doença moral" que proliferava na cidade civilizada, mesmo reprimida a capoeira começou lentamente a adentrar a sociedade, galgando novos horizontes.

$\mathrm{Na}$ busca progressiva por aceitação, a capoeira subiu aos ringues e lutadores das mais diversas lutas estrangeiras foram desafiados em combates oficiais. Suas vitórias espetaculares contribuíram para criar um sentimento de identidade nacional (ABREU, 1999). O processo de ascensão da capoeira começou lentamente na década de 30 e no decorrer dos anos as lutas de ringue ficaram mais incrementadas, bem como o amparo midiático, com os desafios entre a capoeira e as modalidades de jiu-jítsu, luta livre e o cath-can. As vitórias espetaculares dos capoeiristas contribuíram para, gradativamente, organizar um sentimento de nacionalismo, que fora amplamente estimulado pelos jornais locais. E na Bahia as lutas no ringue já faziam parte de uma tradição e de uma diversão popular (ABREU, 1999).

A prática marginalizada ganhou apelo popular quando o capoeirista era visto apenas como um brasileiro que lutava contra um adversário de outra nação. A arte, lentamente, ganhou conotação de esporte nacional, ou seja, a prática inserida em outro contexto mudou seu significado e sua identificação. E recebeu grande destaque quando reafirmava sua capacidade física e eficácia combativa.

Nesse momento, nesse contexto histórico, um grande personagem da história da capoeira entrou em ação: Manuel dos Reis Machado, o Mestre Bimba (1900-1974). Ele foi responsável por um importante divisor histórico que aconteceu por intermédio da modulação que exerceu na arte da capoeira.

Mestre Bimba, em sua luta pela valorização da capoeira, criou em 1928 a "Luta Regional Baiana". Essa denominação teria sido utilizada por ele em substituição ao termo "capoeira", como uma estratégia de aceitação em uma sociedade coberta de

Movimento, Porto Alegre, v. 20, n. 2, p. 735-755, abr./jun. de 2014. 
preconceitos contra a atividade ainda marginalizada. Seu objetivo era, fundamentalmente, diferenciar a sua prática das demais que aconteciam na informalidade das ruas, iniciando-se com ele um processo de "esportivização" da capoeira (VIEIRA, 1995, 1996).

O processo de formação da Capoeira Regional é complexo e foi estudado por muitos autores como: Almeida (1982, 1994), Vieira (1995, 1996), Abreu (1999), e outros, muitos desses alunos do próprio mestre. Nesse momento, cumpre observar que, em síntese, Mestre Bimba, com a ajuda de alguns alunos, e principalmente um deles, chamado Cisnando, grande conhecedor de jiu-jítsu, boxe e luta greco-romana, criou uma metodologia de ensino para a capoeira caracterizada por sequências de movimentos e um código ético rigoroso (ALMEIDA, 1982).

A partir desta transformação, a capoeira foi gradativamente se inserindo no contexto universitário, podendo-se atribuir ao Mestre Bimba um papel importante neste processo, pois através de seu contato com estudantes de Salvador que o convidaram para ensinar na pensão onde residiam, o mestre pode ter acesso a uma camada social e a códigos e símbolos do conhecimento científico que possibilitaram a criação de uma sistematização deste novo modelo de ensino da capoeira. O novo modelo criado por Bimba e seus discípulos passou a ser reconhecido paulatinamente pela sociedade civil, sendo inclusive o Mestre agraciado com o título de Instrutor de Educação Física, mediante diploma expedido pela cidade de Salvador. A capoeira institucionalizada, voltada para o ensino, se inicia com Mestre Bimba, mas só vem se firmar com o passar dos anos, por meio de outras iniciativas promovidas por seus alunos (ALMEIDA, 1994).

De fato, a iniciativa de Mestre Bimba surtiu efeito, merecedora de destaque, a apresentação realizada no palácio governamental em 1937 foi um marco. Ainda clandestina, a capoeira adentrava os salões do governo, a convite do então interventor federal na Bahia, Juracy Magalhães, que levou Mestre Bimba para apresentar a capoeira ao Presidente Getúlio Vargas, no Palácio Presidencial.

Movimento, Porto Alegre, v. 20, n. 2, p. 735-755, abr.jun. de 2014. 
O interventor promoveu o início de descriminalização à luta, e de forma sequencial grandes conquistas aconteceram a Mestre Bimba e a sua vertente. Ainda na mesma década, além do grande sucesso nas lutas de ringue, Mestre Bimba teve sua academia de "Luta Regional Baiana" registrada na Secretaria da Educação, Saúde e Assistência Pública. Também, seu aluno, Mestre Onça Tigre, oficial do Exército, levou Bimba e sua prática para essa instituição (ALMEIDA, 1994).

A vertente de Mestre Bimba se legitimou em um encaixe perfeito entre o nacionalismo da época e os ideais individuais do mestre que se valia de seu capital físico e inteligência estratégica para derrotar não somente os adversários de outras nacionalidades, como também os preconceitos arraigados. $\mathrm{O}$ apelo popular gerado pela sua eficiência e pela formatação de sua luta regional baiana, cercada de códigos acadêmicos e que ainda sobrepujava outras artes, deram, juntamente com os apelos midiáticos, os alicerces para o destaque nacional da capoeira como luta regional baiana.

É importante entender que, nesse período a capoeira se alastrava também paulatinamente pelo território nacional, na região do recôncavo baiano, assim como em Pernambuco, Belém e no Rio de Janeiro, aconteciam iniciativas com características bem peculiares. No Rio de Janeiro, especificamente, um dos grandes eixos de difusão da arte, a capoeira tomava forma completamente distinta da irmã baiana. Uma forma de capoeira desenvolvida lá, que tomou maior vulto também fora denominada de Capoeira de Sinhozinho, que era baseada nas antigas maltas, que tanto perturbaram as autoridades do Rio de Janeiro durante longos anos. As maltas eram grupos organizados de capoeirista do Rio de Janeiro que tiveram seu ápice na segunda metade do século XIX (SOARES, 1996).

Agenor Moreira Sampaio, conhecido como Sinhozinho, aprendeu sua capoeira observando os "bambas" de sua época, convivendo com os boêmios, com os valentes e os malandros do Rio de então. Eles vestiam-se como lutadores de boxe com

Movimento, Porto Alegre, v. 20, n. 2, p. 735-755, abr./jun. de 2014. 
bermudões, botas e sem camisa, seus movimentos estavam, quase que na totalidade dos casos, relacionados às ações diretas de ataque e defesa aproximando-se bastante do que seriam hoje os treinamentos de defesa pessoal. Utilizar indumentárias similares às de outros esportes já aceitos e bem difundidos, talvez tenha sido uma das formas simples, mas eficaz de encontrar aceitação pela estética (HERMANY, 2013).

Os capoeiristas cariocas daquela época estavam em busca de uma identidade cultural própria, construída com base em elementos africanos. As experiências distintas no processo de escravidão geraram agrupamentos diversos que se rivalizavam. Lenços de cores próprias, delimitação de espaços físicos, praças e fontes emolduravam o cenário de disputas e rivalidades entre as maltas bem organizadas. Esse período foi amplamente registrado nos estudos de Soares (1996), a capoeira de Sinhozinho foi baseada nessa herança e teve pouca influência folclórica ou acrobática e também não utilizava os instrumentos musicais característicos da arte.

O desenvolvimento da capoeira no país conta com uma pluralidade identitária e não uma identidade única e exclusiva. Esse fato segue atualmente provocando entre os grupos originários de outras vertentes processos de negação. Negar todas as estruturas que não estão relacionadas a uma concepção própria é uma das fortes estratégias de formação de identidade. Cada grupo específico promove suas ações e fortalece seus argumentos para demonstrar a legitimidade de suas práticas. Grupos distintos possuem características que os diferenciam de outros e cada grupo busca ancorar suas memórias em eixos históricos, que funcionam como referências para obter legitimidade dentro da sua construção de pensamento (POLLAK, 1889).

No processo de aproximação entre a cultura popular e o Estado, muitas foram as formas de reinterpretar a capoeira, seus símbolos, seus rituais e suas memórias. Alguns atores se destacaram utilizando estratégias bem distintas. Nesse contexto, outro

Movimento, Porto Alegre, v. 20, n. 2, p. 735-755, abr.jun. de 2014. 
personagem digno de relevo aparece longe dos holofotes baianos. Inezil Penna Marinho, em 1945³ publicou o livro "Subsídios para o estudo da metodologia do treinamento da capoeiragem", vencedor de um concurso de monografias sobre educação física, promovido pelo Departamento Nacional do Ministério de Educação e Saúde. O livro visava um público erudito, formado preferencialmente pelos professores dessa área do conhecimento. O prefácio do livro escrito por um major, então diretor da Divisão de Educação Física, afirmava a originalidade da capoeira e sua eficiência como luta, bem como os fatores de agilidade, destreza, confiança, lealdade e inteligência e como tal deveria ser conservada (REIS, 2000).

Nessa obra se reafirmava o jeito branco e erudito da capoeira esporte. A educação física militarista abraçava o projeto, enaltecendo principalmente três aspectos: a capoeira mestiça, nacional e esportiva. $\mathrm{O}$ trabalho de Inezil elegia o mulato como o tipo ideal para a capoeira, pois segundo suas palavras o mesmo teria o "tipo ideal da capoeira por ser mais inteligente que o negro e mais destro do que o branco" (REIS, 2000, p.85). Inezil se aprofundou dentro dessa linha de raciocínio, fazendo ampla confusão entre fatores biológicos e culturais, na busca de um discurso legitimador para seu projeto, ele aliou suas ideias a projetos anteriores, como os de Coelho Neto e Annibal Burlamaqui, que vislumbraram a homogeneização da capoeira como uma grande prática nacional com golpes enumerados, inclusos em uma grade curricular onde um instrutor corrigiria os movimentos de ataque e defesa. O ideal dessa capoeira carioca estava bem traduzido nas ações do mestre Sinhozinho, que fora também professor de Inezil.

Os esforços de Annibal Burlamaqui, também conhecido como Zuma, que se tornou o grande influenciador das iniciativas da capoeira carioca, buscavam sua legitimação em um discurso étnico e com bases militaristas. Publicou seu método, em 1928, no livro "Ginástica Nacional: Capoeiragem Metodizada e Regrada", que buscava viabilizar a capoeira como uma modalidade

\footnotetext{
${ }^{3}$ MARINHO, Inezil Penna, Subsídios para o estudo da metodologia do treinamento da capoeiragem, Rio de Janeiro: Imprensa Nacional, 1945.
}

Movimento, Porto Alegre, v. 20, n. 2, p. 735-755, abr.jun. de 2014. 
esportiva brasileira que pudesse ser inserida nas classes mais altas da sociedade carioca. Em síntese, o projeto carioca buscou seu destaque por meio de um "embranquecimento" da capoeira, acoplado aos moldes militares que determinavam os modelos esportivos da época (REIS, 2000).

Paralelamente à movimentação supracitada, outra vertente de capoeira se fortaleceu como um tipo de oposição ao que Mestre Bimba propunha e à exclusividade de arte marcial das outras capoeiras. A capoeira angola de Mestre Pastinha (18891981) prezava pela prática do jogo enquanto expressão artística, buscando, além do aspecto da luta, também aspectos culturais na sua identificação. Mestre Pastinha formou uma escola que divulgava a capoeira como uma manifestação africana, buscando suas raízes nesse continente. Ele fez um grande contraponto em relação à luta regional de Mestre Bimba, buscando divulgar sua capoeira como uma modalidade "tradicional", mãe de todas as outras lutas. Em 1941, fundou também sua escola de capoeira, o "Centro Esportivo de Capoeira Angola", legalizada pelo governo baiano. Apesar de suas ações estarem vinculadas ao viés cultural, a terminologia associada à academia de Mestre Pastinha, "Centro Esportivo", foi uma ação para gerar credibilidade à sua prática. Essa configuação e entendimentos, foram amplamente detalhados nos trabalhos de Vieira, (1996), Reis (2000) e Vassalo (2003).

Dessa forma, a argumentação e o gestual que legitimava a referida vertente buscou na memória histórica seu fortalecimento. $\mathrm{O}$ discurso de Mestre Pastinha associava sua prática às manifestações originárias da África citadas como matrizes da capoeira, como o N'golo ou dança da Zebra.

Mestre Pastinha, um dos mais famosos capoeiristas da Bahia, durante muito tempo pensou que a ginga que aprendera desde criança provinha de uma mistura do batuque angolano e do candomblé dos jêjes, africanos da Costa da Mina, com a dança dos caboclos da Bahia. Mas, por falta de mais conhecimentos, não podia ir muito além dessa afirmação (ASSUNÇÃO; PEÇANHA, 2008, s/p.).

Movimento, Porto Alegre, v. 20, n. 2, p. 735-755, abr.jun. de 2014. 
A estrutura identitária de Mestre Pastinha exemplifica o trabalho de construção de um enquadramento de memória. Michael Pollak (1989) em diálogo com o Henry Rousso (1985) define o enquadramento de memória como a ação de determinados grupos em defender as fronteiras daquilo que o grupo tem em comum, definir seus pontos de referências e fortalecer o seu sentimento de pertencimento (POLLAK, 1989).

Pastinha e seus seguidores criaram um discurso de legitimação de sua prática ancorado na ideia de que ela era a guardiã da ancestralidade negra (ASSUNÇÃO; PEÇANHA, 2008), a despeito da memória oral e os estudos não registrarem nenhuma luta, ou manifestação ancestral específica, oriunda diretamente da África e relacionada fielmente à capoeira. Nesse caso, a fragilidade das informações sobre o surgimento e a origem da capoeira dificulta a perfeita utilização da memória e seu enquadramento, mas evidencia a reconstrução que é feita pelos grupos para afirmar a distinção e relevância de sua identidade particular.

A capoeira prosseguiu fazendo-se viva nas grandes comemorações, nas grandes festas e nas exaltações em datas importantes que são momentos bem propícios para fortalecer o sentimento de pertencimento e a identidade cultural. Não obstante seu aspecto violento, a capoeira nunca perdeu seu status de folguedo, de forma de lazer, nem seu apelo musical. Mesmo Mestre Bimba, adepto do viés combativo, nunca deixou de divulgar e apresentar o samba de roda e outros aspectos folclóricos relacionados à capoeira nos shows que fazia no estado da Bahia e em outros estados. Ela continuou se valendo do apelo folclórico e cultural em diversas oportunidades e também seguiu sendo divulgada por diferentes mestres.

Nesse sentido, a vertente de Mestre Pastinha ganhou significativo impulso em 1937, quando o folclorista Édison Carneiro (1950), após pesquisa sobre a capoeira baiana, declarou que a capoeira de Angola lhe parecia a mais pura. Os levantamentos de Carneiro demonstraram certa confusão entre os estilos de

Movimento, Porto Alegre, v. 20, n. 2, p. 735-755, abr./jun. de 2014. 
capoeira analisados e os toques de berimbau existentes, e não houve também nenhuma revelação em relação aos critérios que o levaram a esta percepção de maior pureza na capoeira Angola (VASSALO, 2003). Apesar disso, essa afirmação reverberou tão fortemente no meio capoeirístico que seus ecos são ouvidos até os dias atuais e inúmeros discursos ancoram seus argumentos nessa ação. "Deste modo, vários capoeiristas procuram se adequar a essa modalidade de jogo considerada mais autêntica, ao mesmo tempo em que a pureza se torna um critério fundamental de distinção e de hierarquização dos praticantes" (VASSALL0, 2003, p.111-112).

$\mathrm{Na}$ década de 40, estudos sobre o folclore ganharam visibilidade, fazendo emergir um paradigma culturalista que buscava as autenticidades e as manifestações que representavam a essência brasileira, para Vassallo (2003), autores como Édison Carneiro, Jorge Amado e Renato Almeida contribuíram com esta perspectiva. Édison Carneiro, por sua vez buscou em seus estudos e em suas pesquisas a capoeira "pura", vinculada à cultura negra, considerada peça fundamental na formação da identidade brasileira. Jorge Amado corroborou com esse pensamento, filtrando personagens da cultura popular entre sambistas e capoeiristas que melhor representavam esse ideal. As descrições da capoeira, por Jorge Amado, dentro deste contexto exaltavam a ludicidade e a percepção pacífica da arte, em que os jogadores pareciam se divertir fingindo lutar. E, ainda segundo Vassallo (2003), Renato Almeida contribuiu bastante com essa linha de raciocínio e também para a polarização das identidades regionais, assinalando a singularidade da capoeira praticada na Bahia em detrimento das outras iniciativas que ocorriam em outros estados.

Letícia Reis (2000) mantendo diálogo com o historiador Eric Hobsbawn traz o conceito da "invenção da tradição" entendendo-a como: "um conjunto de práticas sociais de natureza ritual ou simbólica, que visam inculcar valores e comportamentos por intermédio da repetição, o que implica continuidade em relação a um passado apropriado" (REIS, 2000, p.77). Esse conceito deve ser entendido em uma dimensão ainda maior do que a da

Movimento, Porto Alegre, v. 20, n. 2, p. 735-755, abr.jun. de 2014. 
própria capoeira: observa-se um caráter eletivo na organização das memórias, dos símbolos, dos gestos e uma clara existência de uma disputa política pela hegemonia da pureza da tradição negra - e não só da tradição capoeirística - no país. Alguns segmentos sociais das cidades de Salvador e Rio Janeiro exerciam algumas disputas e rivalizavam na busca de um domínio cultural.

O movimento pela busca das raízes e da ancestralidade presente em inúmeras manifestações culturais atualmente, pode ser estar ancorado na existência de formatações autênticas percebidas em diversas instâncias da cultura brasileira, bem como esforços nostálgicos para construir paradigmas e elos entre o passado pioneiro e o agente da atualidade que difunde a arte. Por intermédio de seus discursos, buscam modular a memória histórica traçando fios condutores perfeitos que legitimam suas formas atuais de abordagem cultural.

A expressão "angola", contida na vertente de Pastinha, remete a uma origem africana e a um passado escravo. A expressão Capoeira Angola foi bem explorada pelos folcloristas e, principalmente, por Édison Carneiro ${ }^{4}$ (1950, apud Vassalo, 2003) que ajudou muito na sua consolidação.

É realmente intrigante a complexidade de nuances que acontecem em torno de um mesmo objeto, bem como as articulações das memórias para a formação do que podemos chamar de realidades construídas (POLLAK, 1992). Nesse sentido, a memória social segue sempre questionadora em relação às delimitações históricas e aos registros formais. "a memória é um campo de lutas e de relação de poder, configurando um contínuo embate entre lembrança e esquecimento" (GONDAR; DODEBEI, 2005, p.7).

Distante dos grandes holofotes midiáticos, na periferia de Salvador, algo diferente de todo contexto já citado acontecia, em um local denominado de Barracão do Mestre Waldemar, um dos grandes pontos de concentração de capoeiristas do Estado da Bahia.

${ }^{4}$ CARNEIRO, Edison. Dinâmica do folklore. Rio de Janeiro: Civilização Brasileira, 1950.

Movimento, Porto Alegre, v. 20, n. 2, p. 735-755, abr./jun. de 2014. 
Mestre Waldemar Rodrigues da Paixão (1916-1990), também conhecido como Waldemar da Liberdade, bairro onde apresentava a capoeira, não estava vinculado à regional de Bimba nem tampouco a Angola de Pastinha. Ele desenvolvia suas rodas dominicais e tornou-se grande referência entre os grandes representantes da arte.

Apesar de seu espaço estar localizado na periferia da cidade, ele recebia grande presença de jornalistas, turistas, estudiosos, intelectuais, artistas e folcloristas, transformando seu Barracão em agência cultural de referência nacional e internacional. "Era comum a presença de Jorge Amado, Pierre Verger, Mario Cravo, Eunice Catunda, Alceu Maynard, Oneyda Alvarenga, Odorico Tavares, Carlos Ott, Caribé e tantos outros" (ABREU, 2003, p.43).

A capoeira, dessa maneira, ascende pelo apelo turístico e como folclore exótico também. Mestre Waldemar comercializou berimbaus durante muitos anos: ele os pintava com cores vibrantes, e sua forma criativa de pintar agradava os turistas. Até os dias atuais podemos ver sua arte replicada nas feiras e mercados onde os instrumentos coloridos criados por Waldemar ficaram imortalizados, tornando-se símbolo da Bahia. Sua estrutura física rústica, por si só, trazia um tom de originalidade. Lugar de diversão e encontro popular, o barracão de Waldemar recebeu artistas de todos os matizes em busca de inspiração (ABREU, 2003).

A seleção de argumentos que ilustram a construção de uma pluralidade de capoeiras revela um processo comum, que acontece além da cultura. Diferentes vertentes e linhas de pensamentos no esporte, ou na educação, apresentam também prioridades e ações distintas. E ideais são confrontados, inevitavelmente, nos constantes ajustes envolvendo processos organizacionais e institucionais. Afastamo-nos, dessa forma, da intenção de montar uma cronologia perfeita entre a organização inicial das vertentes da capoeira até a sua estruturação atual. $O$ presente ensaio provoca o universo acadêmico para o belo instrumento da memória social como processo de formação das identidades nacionais, exemplificados na complexidade das diversas capoeiras.

Movimento, Porto Alegre, v. 20, n. 2, p. 735-755, abr.jun. de 2014. 
A capoeira sofreu inúmeras transformações identitárias ao longo de seu processo de organização e mudanças constantes até os dias atuais. Nos períodos citados, nos quais a capoeira buscou aceitação pelo viés da desportivização, ela pode ser percebida dentro de uma ótica metodizada e institucionalizada, e com certa representação nacional. Mestre Bimba realmente foi um grande agente de transformação, contudo é importante entender o contexto sociopolítico da época, que favoreceu tal transformação. A capoeira conquistou espaço na sociedade, mas foi organizada também dentro de padrões pré-concebidos. Ela foi formatada em um momento político e social propício, durante a "era Vargas", que a absorveu como folclore exótico e luta genuinamente brasileira.

Os estudos de Vieira (1996) trouxeram importantes reflexões que nos dizem que, embora a comunidade da capoeira possa ser definida como um universo simbólico dotado de relativa autonomia, através de suas relações internas, a penetração do espírito político presente nas ideologias autoritárias do período 1930 - 1945 foi percebida. Assim, identificou-se um conjunto de padrões de condutas e gestos articulados em torno do que o autor chamou de "ética da malandragem", uma atitude complexa que envolve, ao mesmo tempo, a resistência e a convivência com instituições que representam o poder e a ordem.

As conquistas sociais não devem ser responsabilizadas apenas pelas ações isoladas dos agentes transformadores, tampouco pela pressão social e a visão estruturalista segundo a qual somos unicamente resultado do contexto sociopolítico em que vivemos. Impossível, contudo, é delimitar todas as forças e ações que ocorrem nos processos de reorganização e construção social. A capoeira, vista como um espaço de representação social que evidencia conflitos que ocorrem também em outras instâncias da cultura brasileira. As complexas formas de inserção da capoeira na sociedade fazem com que nos afastemos de discursos deterministas e muito delimitadores em relação a um formato exclusivo de capoeira.

Movimento, Porto Alegre, v. 20, n. 2, p. 735-755, abr.jun. de 2014. 
Nos processos históricos ressaltados verificamos que a vertente de Mestre Bimba se fez valer pela configuração esportiva, pelo seu capital físico e seus feitos heroicos e ganhou ainda apelo popular e inserção acadêmica; no Rio de Janeiro percebemos o discurso étnico e elitista como forma de legitimar a arte dentro de um contexto estético militarista; Mestre Pastinha buscou relevo por meio do tradicionalismo, do purismo, modulando seus discursos e sua capoeira em torno de um poder original de uma memória histórica; Mestre Waldemar, em seu barracão, ganhou apelo turístico, por meio da capoeira ainda vista como folclore exótico. E em Recife, a capoeira esteve também cercada por mobilizações políticas e intimamente ligada às comemorações e festividades carnavalescas. Ela realmente se espalhou nacionalmente, em diversas formas e contextos, e recebeu um facilitador pelo fato da arte estar imbricada em outras manifestações culturais como no caso do Frevo em Pernambuco e do Boi-Bumbá no Pará (LUSSAC; TUBINO, 2009).

A capoeira trilhou vários caminhos e hoje é aceita como um fenômeno internacional, não somente por meio de sua práxis, mas também pelas suas múltiplas possibilidades de estudo, interpretação e pesquisa que atingiram não somente o Brasil como o mundo. Até o ano 2000 não se podia falar da existência de programas políticos e de ações duradouras do Estado em relação à capoeira. Na atualidade, existem ações governamentais envolvendo órgãos de diversas áreas e um respeito e reconhecimento ao saber popular, bem como aos mestres portadores da sua rica memória histórica (VIEIRA, 2012).

O universo da capoeira foi convidado a olhar para ela com mais profundidade quando o então Ministro da Cultura, Gilberto Gil (2004) discursou para o mundo citando a capoeira como um exemplo brasileiro de tolerância e aceitação, a capoeira, dessa forma, foi convocada a reafirmar suas virtudes. O discurso aconteceu em Genebra em uma convenção das Nações Unidas em homenagem a Sérgio Vieira de Mello, brasileiro e embaixador da ONU, morto em 2003, em um atentado em Bagdá, juntamente com mais 22 pessoas. Todos os mortos eram funcionários da ONU em missão de paz.

Movimento, Porto Alegre, v. 20, n. 2, p. 735-755, abr.jun. de 2014. 
A cultura popular, em destaque a capoeira, inserida em mais de 150 países e dialogando com diversas culturas mundiais, recebeu relevo inigualável na pauta governamental, entre os anos de 2003 e 2011, na gestão do Ministro Gil e de seu sucessor Ministro Juca Ferreira. A partir de 2004, foi criado um plano de ação, incentivo e preservação da arte brasileira, culminando no seu registro como patrimônio cultural brasileiro em 2008. Recebeu grande atenção dos governantes com a instituição de políticas públicas para sua preservação, e todo esse processo de construção e destaque social forneceu riquíssimo material analítico em torno de uma arte que saiu da marginalização e da proibição pelo código penal (1890) para registro como patrimônio cultural brasileiro (IPHAN, 2007).

\section{CONSIDERAÇÕES FINAIS}

E dentro desse contexto pluralizado, seguimos até os dias atuais, após um enquadramento governamental pelo viés da cultura, ainda cercados por embates entre as iniciativas distintas de formatação da capoeira. Temos iniciativas olímpicas, esportiva e federada, temos os enquadramentos da Regional e Angola, temos a iniciativa intitulada de contemporânea, que busca abarcar uma grande complexidade dentro desse universo e temos ainda a capoeira pela capoeira, como simples manifestação popular sem intuitos ou estratégias. Dessa maneira a capoeira segue com múltiplos discursos de legitimação, agora, por vezes, mais ancorados e equalizados ao degrau de ascensão que foi dado pelo seu registro como patrimônio cultural brasileiro.

O estudo da capoeira auxilia diretamente na organização da nossa memória histórica e no entendimento da utilização do corpo e da cultura na formação nacional brasileira. Esperamos contribuir, através da cultura cênica da capoeira, afirmando que o corpo é fonte de amplas significações, possui atitudes e sentimentos e que através de gestos podemos defender valores e ideais por meio de uma comunicação não verbal. Por intermédio do conteúdo agregado, esperamos, finalmente, incentivar o direcionamento dos

Movimento, Porto Alegre, v. 20, n. 2, p. 735-755, abr.jun. de 2014. 
olhares ao foco dos propósitos das intervenções, distanciando-os de juízos de valor, principalmente estéticos e simplistas.

\section{Capoeira: the social memory constructed through the body}

Abstract: The object of this article is to understand, through an analysis of elements of the history of "capoeira", certain search mechanisms for legitimacy in their universe, as well as different forms of organization and expression preserved in the Brazilian memory and culture. It was used the social memory as a reflexive analytical tool to better understand the formation processes of identities in a nation. The text brings the different constructive memories of aspects of Brazilian "capoeira" in dialogue with its recent record as an intangible cultural heritage of Brazil.

Key words: Capoeira. Memory. Cultural characteristics.

Capoeira: la memoria social construida a través del
cuerpo
Resumen: El objetivo de esta investigación fue entender,
mediante un análisis de los elementos en la historia de la
"capoeira", algunas maneras de búsqueda de legitimidad en
su universo, así como sus diferentes formas de organización
y manifestación conservada en la memoria y la cultura
brasileña. Utilizamos la memoria social como instrumento
reflexivo, analítico para entender mejor los procesos de
formación de identidades en una nación. El texto trae la
construcción de algunas vertientes y recuerdos de "capoeira"
brasileña en diálogo con su reciente logro como patrimonio
inmaterial de la cultura de Brasil.
Palabras clave: Capoeira. Memoria. Características
culturais

\section{REFERÊNCIAS}

ABREU, Frederico José de. Bimba é bamba: a capoeira no ringue. Salvador: Instituto Jair Moura, 1999.

ABREU, Frederico José de. O Barracão do Mestre Waldemar. Salvador: Zarabatana, 2003.

ALMEIDA, Raimundo C. A de. Bimba: perfil do mestre. Salvador: Centro Editorial e Didático da UFBA, 1982.

Movimento, Porto Alegre, v. 20, n. 2, p. 735-755, abr./jun. de 2014. 
ALMEIDA, Raimundo C. A de. A saga de Mestre Bimba. Salvador: P\&G, 1994.

ASSUNÇÃO, Matthias Röhrig; PEÇANHA, Cinésio Feliciano (Mestre Cobra Mansa). A dança da Zebra. Revista de História da Biblioteca Nacional, Rio de Janeiro, mar. 2008. Disponível em: http://www.revistadehistoria.com.br/secao/ artigos-revista/elo-perdido. Acesso em: 04 jan. 2012

GIL, Gilberto. Paz no mundo. Discurso proferido em Genebra em 19 de agosto de 2004. Disponível em: http://www.cultura.gov.br/site/2004/08/19/ministro-da-culturagilberto-gil-na-homenagem-a-sergio-vieira-de-mello/. Acesso em: 20 jan. 2012.

GONDAR, Jô; DODEBEI, Vera (org.). O que é memória social? Rio de Janeiro: Contra Capa, 2005.

HERMANY, Rudolf. A capoeira de Sinhozinho: Sinhozinho e a capoeira Carioca. Disponível em: rohermanny.tripod.com. Acesso em: 24 mar. 2013.

IPHAN. Dossiê: Inventário para registro e salvaguarda da capoeira como patrimônio cultural do Brasil. Brasília, 2007.

LUSSAC, Porto Martins Ricardo; TUBINO, Gomes José Manuel. Capoeira: A história e a trajetória de um patrimônio Cultural do Brasil. Revista da Educação Física/UEM, Maringá, v.20, n.1, p.7-16, 1. trim. 2009.

MAUSS, Marcel. As Técnicas Corporais. In: Sociologia e Antropologia, com uma introdução à obra de Marcel Mauss, de Claude Lévi-Strauss. Tradução de Lamberto Puccinelli. São Paulo: EPU, 1974. v. 2

POLLAK, Michael. Memória e identidade social. Estudos Históricos. Rio de Janeiro, v. 2, n.3, p.3-15, 1989.

POLLAK, Michael. Memória, esquecimento e silêncio. Estudos Históricos, Rio de Janeiro, v.5, n. 10, p. 200-2012, 1992.

REIS, Letícia Vidor de Sousa, O mundo de pernas para o ar: a capoeira no Brasil. 2. ed. São Paulo: Publisher Brasil. 2000.

SÁ, Antônio Fernando de Araújo. O cangaço entre e história e a memória. Canindé, n.3, dez.2003.

SOARES, Carlos Eugênio Líbano. A negregada instituição: os capoeiras na corte Imperial 1850 - 1890. Rio de Janeiro, Access, 1996.

VASSALO, Simone Pondé. Capoeiras e intelectuais: a construção coletiva da capoeira "autêntica". Estudos Históricos, Rio de Janeiro,v 2, n.32, p.106-124, 2003.

VIEIRA, Luiz Renato. A história da capoeira IV. A capoeira Regional. Revista Combat Sport, São Paulo, n. 23, maio 1995.

VIEIRA, Luiz Renato. O jogo da capoeira: corpo e cultura popular no Brasil. Rio de Janeiro: Sprint, 1996.

Movimento, Porto Alegre, v. 20, n. 2, p. 735-755, abr./jun. de 2014. 
VIEIRA, Luiz Renato. A capoeira e a cultura internacional-popular. Revista Praticando Capoeira, São Paulo, n.18 set. 2002

VIEIRA, Luiz Renato. A capoeira e as políticas de salvaguarda do patrimônio imaterial: legitimação e reconhecimento de uma manifestação cultual de origem popular. Brasília: Fundação Cultural Palmares, 2012

VIEIRA, Luiz Renato; ASSUNÇÃO, Matthias Röhrig. Os desafios contemporâneos da capoeira. Brasília: Ministério das Relações Exteriores, 2009. (Textos do Brasil, 14: Capoeira)

Endereço para correspondência:

Igor Márcio Corrêa Fernandes da Cunha

SHIN QI 07 conjunto 05 - casa 05 - Lago Norte,

Brasilia - Distrito Federal - CEP: 71.515-050

Recebido em: 25.08.2013

Aprovado em: 16.02.2014

Movimento, Porto Alegre, v. 20, n. 2, p. 735-755, abr.jun. de 2014. 